\title{
Allozyme divergence and phylogenetic relationships among Capra, Ovis and Rupicapra (Artyodactyla, Bovidae)
}

\author{
E. RANDI,* G. FUSCO,* R. LORENZINI,* S. TOSO* \& G. TOSI $\dagger$ \\ * Istituto Nazionale di Bjologia della Selvaggina, ha Cà Fornacetta, 9 Ozzano dell'Emilia fBof italy, and tDipartimento di \\ Biologia, Università di Milano, Via Celoria, 3 Milano, ftaly
}

\begin{abstract}
Genetic divergence and phylogenetic relationships between the chamois (Rupicaprini, Rupicapra nupicapra rupicapra) and three species of the Caprini (Capra aegagrus hircus, Capra ibex ibex and Ovis ammon musimon) have been studied by multilocus protein electrophoresis. Dendrograms have been constructed both with distance and parsimony methods. Goat, sheep and chamois pairwise genetic distances had very similar values. All the topologies showed that Capra, Ovis and Rupicapra originate from the same internode, suggesting the hypothesis of a common, and almost contemporaneous, ancestor. The estimated divergence times among the three genera ranged from 5.28 to $7.08 \mathrm{Myr}$. These findings suggest the need to reconsider the evolutionary relationships in the Caprinae.
\end{abstract}

Keywords: allozymes, Caprinae, electrophoresis, phylogenetic trees.

\section{Introduction}

The evolutionary relationships of the subfamily Caprinae (Artyodactyla, Bovidae; Corbet, 1978) have been discussed by Geist (1971) within the framework of his dispersal theory of Ice Age mammal evolution. Several sources of information (zoogeography, ecoethology, morphology, and karyology) support the hypothesis that the Rupicaprini are the ancestral group from which two independent lineages evolved (the Caprini and the Ovibovini) by dispersal from the tropical centre of origin into temperate and arctic regions.

Implications of the model are that the Rupicaprini are distantly related to Ovis and Capra; and that Ovis and Capra are closely related sister genera. The timescale of these relationships is almost completely obscure. The fossil records document the ancient origin of the Rupicaprini. They were widely distributed during the Miocene/early Pliocene (Thenius \& Hofer, 1960), and the Pliocenic fossils witness an intensive period of rupicaprid speciation. But the fossils are not particularly abundant, nor well studied, so the ancestral lineages of the modern genera have not been determined.

The origin of the Caprini is completely unclear. Pilgrim (1947) supposed the existence of a separate caprid lineage since the lower or middle Miocene. Shaller (1977) agrees with the outline given by Thenius \& Hofer (1960) supporting the idea of a more recent origin of the Caprini, and in particular of a Pliocenic splitting of Ovis and Capra. In Geist's (1971) opinion the divergence between $O v i$ s and Capra could have been a consequence of the Villafranchian early glaciations. Payne (1968) follows the extreme point of view of a very recent (Holocene) origin of $O y i s$, perhaps as a by-product of early domestication.

Recent electrophoretic research (Randi et al., 1989; Hartl et al., 1990) has shown genetic distance values of similar magnitude among the genera Rupicapra, Ovis, and Capra. These results, although preliminary because of the low sample sizes studied, are discordant with current opinions, and raise interesting questions on the tempo and mode of the evolution of the Caprinae.

In this paper we re-address the problem and extend the previous findings using new biochemical-genetic data obtained with multilocus protein electrophoresis of a large sample of loci and specimens. Genetic distances, dendrograms and phylogenetic trees have been computed with different methods. The results concordantly support the hypothesis of a common, and almost contemporaneous, ancestor of the genera Rupicapra, Ovis and Capra. 


\section{Materials and methods}

Direct side-by-side comparisons of single locus electrophoretic protein mobility have been performed on specimens of domestic goat (Capra aegagrus hircus, $n=20$ ) obtained from a local abattoir, Alpine ibex (Capra ibex ibex, $n=20$ ), from the Piz Albris colony, Graubünden, Switzerland, European mouflon (Ovis ammon musimon, $n=10$ ) and chamois (Rupicapra rupicapra rupicapra, $n=20$ from Valle Belviso, Italian Alps. A single ox (Bos primigenius taurus $\rangle$ has been used as an outgroup. Heart and liver tissues were homogenized in $0.01 \mathrm{M}$ Tris $/ \mathrm{HCl}, \mathrm{pH} 7.5(+0.001 \mathrm{M}$ $\beta$-mercaptoethanol) buffer, centrifuged at $12,000 \mathrm{rpm}$ for $15 \mathrm{~min}$; the supernatant was collected in Microtitre plates and stored at $-80^{\circ} \mathrm{C}$ until processed. Vertical polyacrylamide gel (PAGE, $7.5 \%$ acrylamide concentration) and cellulose acetate membrane (CAM, Sartorius) electrophoresis resolved 33 presumptive loci. The following electrophoretic conditions were used (multiple loci are numbered starting from the most anodal).

PAGE: 1. Discontinuous Tris/glycine, pH 8.3 (Davis, 1964); malate dehydrogenase (MDH-1, 1.1.1.37); superoxide dismutase (SOD-1, SOD-2, 1.15.1.1); Iactate dehydrogenase ( $\mathrm{LDH}-1, \mathrm{LDH}-2,1.1 .1 .27$ ); fumarase (FUM, 4.2.1.2); haemoglobin (HB-1, HB-2); albumin (ALB); non-enzymatic heart proteins (H-PT$1,-2)$; post-albumin (P-ALB); malic enzyme (ME-1, 1.1.1.40); mannose phosphate isomerase (MPI, 5.3.1.8); hexokinase (HK, 2.7.1.1); glucose-6phosphate dehydrogenase (G-6-PDH, 1.1.1.49); $\alpha$ glycerolphosphate dehydrogenase ( $\alpha$-GPDH, 1.1.1.8); creatine kinase (CK-1, CK-2, 2.7.3.2); peroxidase (POX-1, 1.11.1.7). 2. Discontinuous Tris/glycine, $\mathrm{pH}$ 8.5 (Jolley and Allen, 1965) aspartate aminotransferase (AAT-1, 2.6.1.1); phosphoglucose isomerase
(PGI, 5.3.1.9); phosphoglucomutase (PGM, 2.7.5.1). 3 . Tris/borate, pH 8.9 (Studier, 1973): $\alpha$-naphtylacetate heart and liver esterase (EST-1 through -6, 3.1.1.1).4. Lithium hydroxide, pH 8.6 (Ferguson, 1980): leucylalanine liver peptidase (PEP-1, PEP-2, 3.4.11.). CAM (Grunbaum, 1981) 1. Tris/maleate, pH 7.4: 6-phosphogluconate dehydrogenase (6-PGD, 1.1.1.44). 2. Citrate/phosphate, $\mathrm{pH}$ 7.0: isocytrate dehydrogenase $(\mathrm{IDH}-1,1.1 .1 .42)$. Staining recipes were adapted from Harris \& Hopkinson (1976) and from Grunbaum (1981).

Alleles were coded by letters, ' $a$ ' being the most anodal. Allele frequencies, 12 different measures of genetic distances and dendrograms (UPGMA, WPGMA, Wagner, KITSCH, FITCH) have been computed using several programs (Table 1). Moreover, the alleles were coded as characters with two states, 1 (presence) and 0 (absence), according to the independent allele model (Buth, 1984), and parsimony phylogenetic trees (i.e. HENNIG86, PAUP, JACKPAUP, BOOT) have been obtained with the programs listed in Table 1.

\section{Results}

Allele frequencies in the four species of the Caprinae and in the outgroup Bos primigenius taurus are listed in 'Table 2. Nei's (1978) standard unbiased and Rogers' (1972) genetic distance matrix are shown in Table 3. Although Nei's and Rogers' genetic distance values are different in magnitude, due to their different mathematic formulations, they are inter-correlated, thus giving the same information. Goat, sheep and chamois pair-wise genetic distances are very similar, ranging from 0.59 (between Rupicapra r. nipicapra and Capra i. ibex) to 0.68 (between Capra aegagrus hircus and Ovis ammon musimon).

Table 1 Computer programs and methods used to obtain genetic distances, dendrograms and phylogenetic trees

\begin{tabular}{|c|c|c|}
\hline $\begin{array}{l}\text { Computer } \\
\text { package }\end{array}$ & Method & References \\
\hline \multirow[t]{3}{*}{ BIOSYS-1 $1^{a}$} & Genetic distances & Swofford \& Selander, 1989 \\
\hline & UPGMA and WPGMA dendrograms & Sneath \& Sokal, 1973 \\
\hline & Wagner trees & Farris, 1972 \\
\hline \multirow[t]{2}{*}{ PHYLIP' } & FITCH and KITSCH trees & Felsenstein, 1979 \\
\hline & BOOT - bootstrap consensus tree & Felsenstein, 1985 \\
\hline HENNIG86 ${ }^{c}$ & Parsimony trees & Farris, 1988 \\
\hline PAUPd & Parsimony trees & Swofford, 1985 \\
\hline JACKPAUP $^{e}$ & Jack-knife consensus trees & Lanyon, 1985 \\
\hline
\end{tabular}

${ }^{a}$ Swofford \& Selander, 1989; ${ }^{b}$ Felsenstein, 1989; cFarris, 1988; 'Swofford, 1985;

'Lanyon, 1985. 
Table 2 Distribution of the electromorphs and allelic frequencies at 27 loci in four species of the Caprinae and in the outgroup Bos primigenius taurus. Abbreviations:

C.a.h. $=$ Capra aegagrus hircus; R.r.r. $=$ Rupicapra r rupicapra; O.a.m. = Ovis ammon musimon; C.i.i. = Capra i. ibex; B.p.t. $=$ Bos primigenius tauns. ${ }^{\text {a }}$

\begin{tabular}{|c|c|c|c|c|c|}
\hline \multirow[b]{2}{*}{ Locus } & \multicolumn{5}{|c|}{ Species } \\
\hline & Ca.h. & R.r.г. & O.a.m. & C.i.i. & B.p.t. \\
\hline AAT-1 & a & $\mathrm{a}$ & $\mathrm{a}$ & $a$ & $\mathbf{b}$ \\
\hline FUM & $a$ & $\mathrm{a}$ & $\mathbf{a}$ & $\mathrm{a}$ & b \\
\hline MPI & $\mathrm{b}$ & $\mathrm{a}$ & $\mathrm{a}$ & b & $c$ \\
\hline LDH-1 & $\mathrm{b}$ & $\mathrm{b}$ & $\mathrm{b}$ & b & a \\
\hline$a-\mathrm{GPDH}$ & $\mathbf{a}$ & a & $\mathrm{a}$ & $\mathbf{a}$ & $b$ \\
\hline 6-PGD & $\mathrm{b}$ & $c$ & $\mathrm{a}$ & $\mathbf{b}$ & $\mathrm{c}$ \\
\hline $\mathrm{HK}$ & b & $c$ & $\begin{array}{l}\mathrm{a}(0.600) \\
\mathrm{d}(0.400)\end{array}$ & b & $\mathrm{e}$ \\
\hline EST-1 & $\mathrm{a}$ & $b$ & $\mathrm{c}$ & $\mathrm{a}$ & $d$ \\
\hline EST-2 & b & $d$ & $c$ & b & $a$ \\
\hline EST-3 & $\mathrm{a}$ & $\mathrm{c}$ & d & b & $e$ \\
\hline EST-4 & b & a & $\mathrm{b}$ & $b$ & $c$ \\
\hline EST-5 & $\mathrm{a}$ & $\mathrm{c}$ & d & b & $\mathrm{e}$ \\
\hline EST-6 & $\mathrm{b}$ & $\mathrm{c}$ & $c$ & $\mathrm{c}$ & a \\
\hline PEP-1 & $\mathrm{a}$ & $\mathbf{b}$ & $c$ & $\mathrm{a}$ & $\mathrm{d}$ \\
\hline PEP-2 & $\mathrm{b}$ & $\mathrm{e}$ & $\mathrm{d}$ & $\mathrm{a}$ & $c$ \\
\hline IDH- 1 & $\mathrm{a}$ & $\begin{array}{l}c(0.800) \\
\mathrm{e}(0.200)\end{array}$ & $\begin{array}{l}\mathrm{d}(0.800) \\
\mathrm{f}(0.200)\end{array}$ & $a$ & b \\
\hline $\mathrm{P}-\mathrm{A} \perp \mathrm{B}$ & $\mathrm{a}$ & $\mathrm{b}$ & $\mathrm{c}$ & $\mathrm{a}$ & $d$ \\
\hline ALB & $\mathrm{a}$ & b & $\mathrm{c}$ & $\mathrm{a}$ & $\mathrm{d}$ \\
\hline HB-1 & $b$ & b & $\mathrm{b}$ & b & $\mathrm{a}$ \\
\hline HB-2 & a & a & $\mathrm{a}$ & a & b \\
\hline H-PT-1 & $\mathrm{b}$ & b & $b$ & $\mathbf{b}$ & $\mathbf{a}$ \\
\hline H-PT-2 & b & $b$ & b & $\mathrm{b}$ & $\mathrm{a}$ \\
\hline G-6-PDH & $\begin{array}{l}b(0.625) \\
c(0.375)\end{array}$ & $a$ & $\begin{array}{l}e(0.700) \\
f(0.300)\end{array}$ & $\mathbf{b}$ & $\mathrm{d}$ \\
\hline ME-1 & $\begin{array}{l}a(0.625) \\
b(0.375)\end{array}$ & $\begin{array}{l}\mathrm{b}(0.400) \\
\mathrm{c}(0.600)\end{array}$ & $\begin{array}{l}d(0.400) \\
e(0.100) \\
f(0.500)\end{array}$ & $a$ & $\mathrm{e}$ \\
\hline LDH-2 & $\mathrm{b}$ & $\mathrm{b}$ & $\mathrm{b}$ & b & $\mathrm{a}$ \\
\hline SOD-1 & $b$ & $\mathrm{~b}$ & $\mathrm{c}$ & $b$ & $a$ \\
\hline SOD-2 & $\mathrm{b}$ & $\mathrm{b}$ & $c$ & $\mathrm{~b}$ & a \\
\hline
\end{tabular}

The following loci were monomorphic among the species: MPI, PGI, MDH-1, POX-1, CK-1, CK-2.

UPGMA tree, computed using Nei's standard unbiased genetic distance, is shown in Fig. 1A. Identical UPGMA and WPGMA trees (not shown) were obtained with all the different genetic distances computed using BIOSYS-1 (Swofford \& Selander, 1989). The Wagner tree with Rogers' genetic distances, rooted using Bos as an outgroup, is presented in Fig. 1B. It is identical with those of UPGMA and WPGMA. A common feature of all the distance trees is the origin of the lineages leading to Capra, Ovis and Rupicapra
Table 3 Nei's (1978) standard unbiased (below the diagonal) and Rogers' (1972) distances (above) among four species of the Caprinae and the outgroup Bos primigenius taums. (For the abbreviations, see Table 2.)

\begin{tabular}{llllll}
\hline & C.a.h. & R.r.r. & O.a.m. & C.i.i. & B.p.t. \\
\hline C.a.h. & - & 0.467 & 0.492 & 0.144 & 0.811 \\
R.r.r. & 0.624 & - & 0.463 & 0.448 & 0.781 \\
O.a.m. & 0.676 & 0.618 & - & 0.470 & 0.802 \\
C.i.i. & 0.139 & 0.592 & 0.632 & - & 0.818 \\
B.p.t. & 1.688 & 1.537 & 1.657 & 1.705 & - \\
\hline
\end{tabular}

from the same internode, pointing out a possible common ancestor. Due to the small genetic distances (Nei's $D=0.139$, Rogers' $D=0.144$ ), goat and ibex are phylogenetically more closely related. Goodness-of-fit statistics are very high, indicating low levels of homoplasy in the dataset. Identical topologies have been obtained with the programs FITCH and KITCH (not shown).

Two maximum parsimony trees were obtained by HENNIG86 (Fig. 2A,B). Ovis and Rupicapra can change their respective relationships without modifying the length of the tree. Two statistical manipulations of the discrete dataset have been performed. Bootstrapping of characters was carried out by BOOT. The majority rule consensus tree obtained after 50 replicates is shown in Fig. 2C. The relationship of Rupicapra with the other taxa is not stable, since it recurred only 25 out of 50 runs. Jack-knifing of taxa was applied by JACKPAUP, and the strict consensus tree is shown in Fig. 2D. As expected from the HENNIG86 and BOOT results, the cladistic relationships among Rupicapra, Ovis and Capra are not fully resolved, and the tree indicates a trichotomy.

\section{Discussion}

Multilocus enzyme electrophoresis of taxa belonging to the subfamily Caprinae yielded unexpectedly similar genetic distance values among the genera Rupicapra, Capra and Ovis. This is in contrast to the current opinion of an early origin of the tribe Rupicaprini, and of a subsequent recent evolution of the tribe Caprini.

Information from non-genetic data are not particularly useful to evaluate these results. The rather poor fossil records have been used to date the splitting between Ovis and Capra in a wide range of time, spanning from the upper Miocene (Pilgrim, 1947) to the middle Pleistocene (Payne, 1968). Karyotypes have been quite well studied in this subfamily (Bunch \& Nadler, 1980). The most plausible mechanism of chromosome evolution in the Bovoidea could be a 


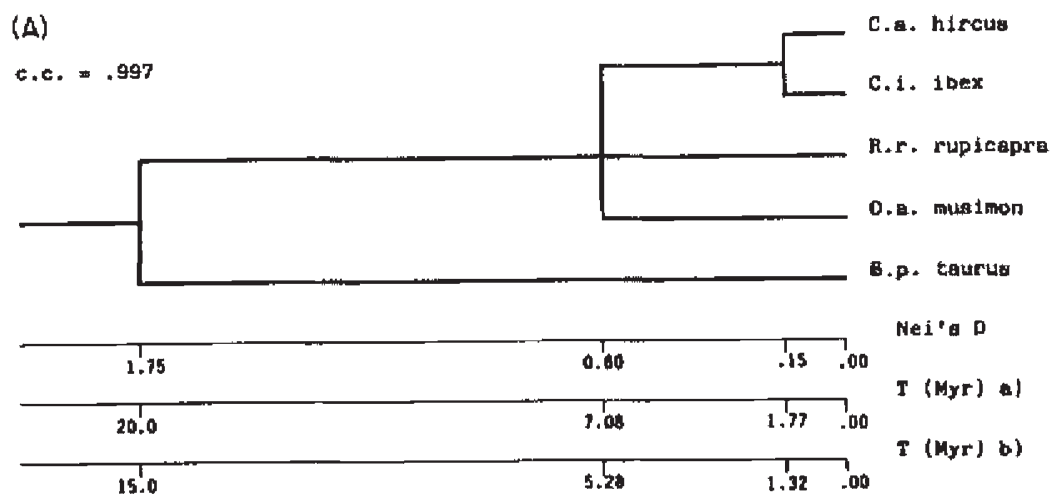

(B)

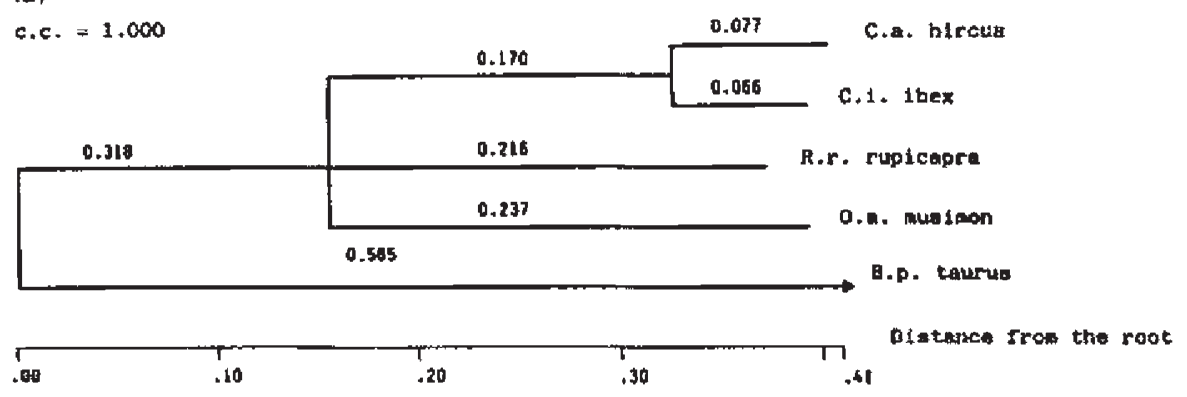

Fig. 1 (A) UPGMA dendrogram obtained with Nei's (1978) standard unbiased genetic distances. Time scales according to (a) the lower and (b) the upper divergence time. (B) WAGNER tree computed with Rogers' (1972) genetic distances and rooted using Bos as outgroup. c.c. $=$ cophenetic correlation.

(A)

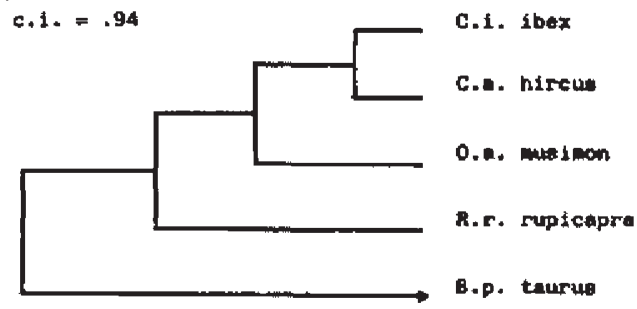

(B)

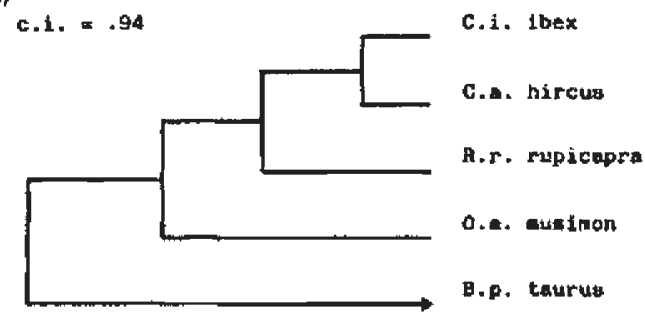

(C)

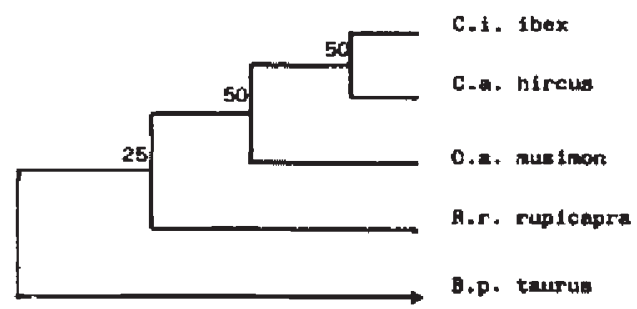

(D)

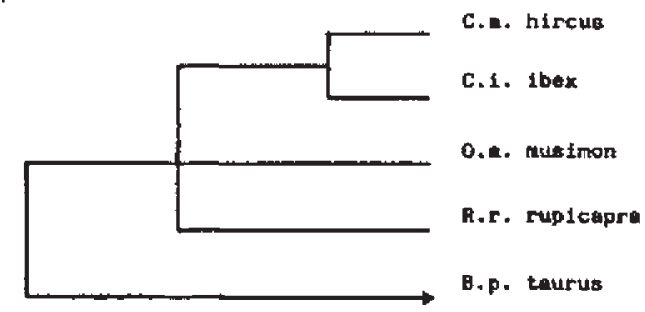

Fig. 2 Phylogenetic relationships between the Caprini and Rupicapra: (A) and (B) Maximum parsimony trees (HENNIG86); (C) Majority rule consensus tree. Numbers at the internodes give the occurence of the internode over 50 bootstrap replicates (BOOT); (D) Jack-knife strict consensus tree (JACKPAUP). All trees are rooted with Bos as outgroup. c.i. = consistency index.

pattern of Robertsonian fusions, proceeding from an ancestral $2 n=60 \quad(\mathrm{NF}=60)$ acrocentric karyotype (Wirster \& Benirschke, 1968) to a derived lower $2 n$ karyotype. This makes it difficult to infer unambiguous phylogenetic relationships in the Caprinae. In fact, the Rupicaprini (postulated to be ancestral) have lost the primitive high chromosome number (i.e. $2 n=42$ in Oreamnos, 58 in Rupicapra, 50 in Capricomis crispus, 48 in Capricornis sumatrensis, 56 in Nemorhaedus), while the genus Capra (postulated to be derived) has conserved the ancestral $2 n=60$ karyotype (Bunch \& Nadler, 1980). 
The distance matrix and parsimony trees we have obtained using multilocus enzyme electrophoresis are consistent with each other, and with the observed dataset (high indexes of goodness-of-fit). It is well known that phylogenies could be drawn reliably if the rates of molecular evolution are constant along the different lineages of a tree (Farris, 1972). Variance in the rates of molecular evolution could produce different branching patterns if the trees are computed with or without the constraint of a molecular clock (i.e. UPGMA, WPGMA and KITSCH, or WAGNER and FITCH algorithms, respectively). All the topologies we have obtained are identical, irrespective of the imposition of regular rates of protein evolution. A relative-rate test (Beverley \& Wilson, 1984) can be applied to test for rate constancy. It is easy to see (Fig. 1B) that the ratios between each pair of lineages (using Bos as an outgroup) are close to 1.0 , strongly supporting the existence of a regular rate of protein evolution and therefore of a molecular clock.

Goodman et al. (1982) estimated the divergence time between the Bovinae and the Caprinae (15-20 million years (Myr)) from amino acid sequence and paleontological data. We could calibrate the rate of protein evolution using these values to obtain the actual clock. Nei's standard unbiased average genetic distance between the Bovinae and the Caprinae, as estimated by multilocus enzyme electrophoresis, is $\bar{D}=1.75$, so we can compute $1 D=15 / 1.75=11.8$ Myr, and $1 D=20 / 1.75=8.8 \mathrm{Myr}$, by taking into account, respectively, the lower and the upper proposed divergence time. Time-scales are drafted in Fig. 1A. The divergence time between Capra aegagrus and Capra ibex ranges from 1.32 to $1.77 \mathrm{Myr}$ (early Pleistocene); the divergence among the genera Capra, Ovis and Rupicapra ranges from 5.28 to $7.08 \mathrm{Myr}$ (Miocene).

These results are in accordance with an estimated 6-11 per cent mitochondrial DNA nucleotide divergence between sheep and goat (Upholt \& Dawid, 1977), and with $\beta-\mathrm{A}, \beta-\mathrm{C}$ and globin genes DNA sequence data ( $\mathrm{Li} \&$ Gojobori, 1983). Using the average rate of 2 per cent mitochondrial DNA sequence divergence/Myr (Wilson et al., 1985), we obtain a divergence time between sheep and goat ranging from 3.0 to $5.5 \mathrm{Myr}$. The estimated rate of substitution per site per year in the globin genes, $r=4.6 \times 10^{-9}$ ( $\mathrm{Li} \&$ Gojobori, 1983), allows the computation of a divergence time of 5.0 Myr.

Since three independent sources of molecular data (protein, mitochondrial DNA, nuclear DNA), converge to estimate an average divergence time around 5.0 Myr between sheep and goat, we are confident that a similar divergence time between Rupicapra and the Caprini, estimated by multilocus enzyme electrophoresis, is correct also.

At least two population genetic factors could complicate the interpretation of electrophoretic results. If speciation follows a quick and contemporaneous segregation of several lineages from an ancestral highly polymorphic population, then a fast increase in genetic distances among lineages is expected (Nei, 1976). During this phase, genetic distance and divergence time will not be correlated linearly. But this effect is unlikely to persist after several million years of independent evolution, and it is very difficult to imagine an ancestral rupicaprid population with such a high amount of polymorphism to explain the actual percent of fixed differences (about 45 per cent; Table 2) among goat, sheep and chamois.

Hybridization and gene flow could reduce the genetic distance if two taxa come into secondary contact. The evolution becomes reticulate and deriving phylogenetic trees from genetic distance data becomes a problematic task (Thorpe, 1983). In this case, hybridization and gene flow between chamois and sheep need to be postulated if we want to reconcile the estimated genetic values with the current evolutionary opinions. This event seems to be improbable both from paleontologic and biogeographic points of view (Geist, 1971; Shaller, 1977).

These results will be better interpreted when more species belonging to the subfamily Rupricaprini have been studied. It will be particularly important to elucidate the evolutionary relationships among the different Rupicaprini lineages (the primitive tropical forms, the North-American lineage, the advanced genus Rupicapra), in order to resolve their inter-relations with Ovis and Capra, as well as with the so-called intermediate forms (Hemitragus, Ammotragus).

\section{Acknowledgements}

We thank P. Ratti and M. Giacometti (Fish and Game Service, Graübunden, Switzerland), D. Marniga and G. Colombi Azienda Faunistica Valle Belviso, Barbellino) for helping us in sample collection. G.T. has been supported by a grant from Ministero della Pubblica Istruzione (Roma). We are grateful to the anonymous referees whose suggestions greatly improved the manuscript.

\section{References}

BEVERLEY, S. M. AND WILSON, A, c. 1984. Molecular evolution in Drosophila and the higher Diptera. II. A time scale for fly evolution. J. Mol. Evol, 21, 1-13. 
BUNCH, T. D. AND NADLER, C. F. 1980. Giemsa-band patterns of the tahr and chromosomal evolution of the tribe Caprini. J. Hered., 71, 110-116.

BUTH, D. I. 1984. The application of electrophoretic data in systematic studies. Ann. Rev, Ecol. Syst, 15, 501-522.

CORBET, G. B. 1978. The mammals of the Palaearctic Region. British Museum (Natural History). Cornell University Press, Ithaca, New York.

DAvIS, B. J. 1964. Disc electrophoresis. II. Method and application to human serum proteins. Ann. N. Y. Acad. Sci., $121,404-427$.

FARRIS, J. S. 1972. Estimating phylogenetic trees from distance matrices. Am. Nat. 106, 645-688.

FARRIS. J. s. 1988. HENNIG86. Reference Manual. Version 1.5 .

FELSENSTEIN, J. 1979. Alternative method of phylogenetic inferences and their interrelationships. Syst. Zool, 28, 49-62.

FEI.SENSTEIN, J. 1985. Confidence limits on phylogenies: an approach using the bootstrap. Evolution, 39, 783-791.

FELSENSTEIN, 1. 1989. PHYLIP. Phylogenetic inference package. Version 3.2. University of Washington, Seattle, Washington.

FERGUSON, A. 1980. Biochemical Systematics and Evolution. Blackie, Glasgow and London.

GEIST, Y, 1971. Mountain sheep, A study in behavior and evolution. University of Chicago Press. Chicago.

GOODMAN, M., WEISS, M. L. AND CZELUSNiAK, J. 1982. Molecular evolution above the species level: branching pattern, rates, and mechanisms. Syst. Zool., 31, 376-399.

GRUNBAUM, B. w. (ed.) 1981. Handbook for forensic individualization of human blood and bloodstains. Sartorius GmbH, Gottingen.

HARRIS, H. AND HOPKINSON, D. A. 1976. Handbook of enzyme electrophoresis in human genetics. North Holland Publ, Amsterdam.

HARTL, G. B., BURGER, H., WILLING, R. AND SUCHENTRUNK, F. 1990. On the biochemical systematics of the Caprini and the Rupicaprini, Bioch. Syst. Ecol., 18, 175-182.

JOLLEY, w. B. AND ALLEN, H. w. 1965. Formation of complexes between basic proteins of leucocytes and plasma globulins. Nature, 208, 390-391.

LANYON, S. M. 1985. Molecular perspective on higher-level relationships in the Tyrannoidea (Aves). Syst. Zool., 34, 404-418.

L, W. AND GOJOBORI, T. 1983. Rapid evolution of goat and sheep globin genes following gene duplication. Mol. Biol. Evol., 1, 94-108.

NEI, M. 1976. Mathematical models of speciation and genetic distance. In: Karlin, S. and Nevo, E. (eds), Population Genetics and Ecology. Academic Press, London, pp. 723-765.

NEI, M. 1978. Estimation of average heterozygosity and genetic distance from a small number of individuals. Genetics, 89, 583-590.

PAYNE, S. 1968. The origins of domestic sheep and goats: a reconsideration in the light of the fossil evidence. Proc. Prehist. Soc., 34, 368-384.

PILGRIM, G. E. 1947. The evolution of the buffaloes, oxen, sheep and goats, I. Limn. Soc. London, 41, 272-286.

RANDI, E., TOSI, G. AND TOSo, s. 1989. Genetic variation and phylogenetic relationships among some Caprinae. World Conf. Mountain Ungulates. Camerino, 4-6 September.

ROGERS. J. S. 1972. Measures of genetic similarity and genetic distances. Studies in Genetics, VII. University of Texas Publ., 7213, 145-153.

SHAller, G. B. 1977. Mountain monarchs. Wild sheep and goats of the Himalaya. University of Chicago Press, Chicago.

SNEATH, P. H. A. AND SOKAL, R. R. 1973. Numerical taxonomy. Freeman W. H. and Co., San Francisco.

STUDIER, F. W. 1973. Analysis of bacteriofage T 7 early RNAs and proteins on slab gel. J. Mol. Biol., 79, 273-275.

SWOFFORD, D. L. 1985. PAUP, Phylogenetic analysis using parsimony, version 2.4. Illinois Nat. Hist. Survey, Champaign, Illinois.

SWOFFORD, D. L. AND SELANDER, R. B. 1989. BIOSYS-1. A computer program for the analysis of allelic variation in population genetics and biochemical systematics. Release 1.7. Illinois Nat. Hist. Survey, Champaign, Illinois.

THENIUS, E. AND HOFER, H. 1960. Stammesgeschichte der Säugetiere. Springer-Verlag, Berlin.

THORPE, R. s. 1983. Phylogenetic analysis of range expansion in the grass snake: reticulate evolution: primary and secondary contact zone. Pp. 464-468. In: Felsenstein, J. (ed.), Numerical Taxonomy. NATO ASI. Series G No, 1 Springer Verlag, Berlin, Heidelberg.

UPHOLT, w. B. AND DAWID, I. в. 1977. Mapping of mitochondrial DNA of individual sheep and goats: rapid evolution in the $\mathrm{D}$ loop region. Cell, 11, 571-583.

WILSON, A. C., CANN, R, L., CARR, S. M., GEORGE, M., GYLLENSTEN, U. HELM-BYCHOWSKI, K. M., HIGUCHI, R. G., PALUMBI, S. R., FRAGER, E. M., SAGE, R. D. AND STONEKING, M. 1985. Mitochondrial DNA and two perspectives on evolutionary genetics. Biol. $J$ Linn. Soc., 26, 375-400.

WURSTER, D. H. AND BENIRSCHKE, K. 1968. Chromosome studies in the Superfamily of Bovoidea. Chromosoma, 25, 152-171. 